\title{
50 years of "The Pill": celebrating a golden anniversary
}

\author{
Anne Szarewski, Diana Mansour, Lee P Shulman
}

\begin{abstract}
The past 50 years have seen great advances in combined oral contraceptives (COCs) that have resulted in reduced risks of adverse events and improved cycle control. The most important changes in COCs over time include repeated lowering of the estrogen dose, development of new progestogens, and the reduction or elimination of the pill-free interval. Most recently, formulations that deliver estradiol in lieu of ethinylestradiol have been introduced. The advantages of COCs generally far outweigh the disadvantages. Current options in oral contraception
\end{abstract}

include a wide spectrum of products that enable clinicians to choose the most appropriate formulation for individual women. This article summarises the advances in oral contraceptives over time and describes the most current clinical data regarding the use of COCs.

Keywords combined oral contraceptives, venous thromboembolism

J Fam Plann Reprod Health Care 2010; 36(4): 231-238

(Accepted 27 July 2010)

\section{Introduction}

The launch of Enovid-10 ${ }^{\circledR}$ (G D Searle Co., Skokie, IL, USA), the first combined oral contraceptive (COC), in 1960 revolutionised family planning by giving women control over their own fertility. The social, political and economic implications were so profound that although countless oral medications have been approved both before and after this event, the contraceptive pill is the only one to be known as "The Pill". Indeed, it was Aldous Huxley who first used the term, with eerie foresight, in his essay Brave New World Revisited, published in 1958. Today, half a century later, over 100 million women worldwide use oral contraceptives. ${ }^{1}$ Although increased contraceptive use has been accompanied by a trend towards fewer abortions, ${ }^{2}$ unplanned pregnancies remain prevalent and their social, health and environmental consequences pose a contemporary global challenge, ${ }^{3}$ with population control being described as the "greatest challenge facing humanity". 4 Here we review half a century of oral contraceptive use; examine how and why The Pill has evolved; describe the contraceptive needs of changing societies; and discuss current and emerging issues and developments related to birth control.

\section{Importance of contraception}

Over 200 million women worldwide seek, but do not have access to, modern contraceptives. 5 Lack of reliable contraceptive methods increases the risk of unintended/unplanned pregnancies and its associated

Cancer Research UK Centre for Epidemiology, Mathematics and Statistics, Wolfson Institute of Preventive Medicine, London, UK

Anne Szarewski, PhD, FFSRH, Clinical Consultant and Honorary Senior Lecturer

Sexual Health Services, New Croft Centre, Newcastle upon Tyne, UK

Diana Mansour, FRCOG, FFSRH, Clinical Director

Feinberg School of Medicine, Northwestern University, Chicago, IL, USA

Lee P Shulman, MD, Professor of Obstetrics and Gynecology

Correspondence to: Anne Szarewski, Clinical Consultant and Honorary Senior Lecturer, Cancer Research UK Centre for Epidemiology, Mathematics and Statistics, Wolfson Institute of Preventive Medicine, Charterhouse Square, London EC1M 6BQ, UK. E-mail: a.szarewski@qmul.ac.uk

\section{Key message points}

- Advances in combined oral contraception over the past half century include reductions in hormone doses, development of more selective progestogens, and changes in dosing regimens, all of which have improved the safety and tolerability profiles of combined oral contraceptives (COCs).

- The most recent advance in the evolution of COCs is the introduction of formulations with $17 \beta$-estradiol, which is identical to endogenous estrogen.

morbidity and mortality. Among 210 million pregnancies each year, $38 \%$ are unplanned and $22 \%$ end in abortion. 3,6 In the USA, nearly half of the approximate 6.5 million annual pregnancies are unintended, resulting in approximately US\$5 billion in direct medical costs. ${ }^{7}$ An estimated 5 million women in 13 developing countries are hospitalised each year due to abortion-related haemorrhage, sepsis or other complications. ${ }^{8}$ Unsafe abortions are responsible for approximately 70000 deaths each year, accounting for an estimated $13 \%$ of maternal deaths worldwide 9 and for the orphaning of approximately 220000 children. ${ }^{10}$ Unsafe abortion also poses a significant economic burden and long-term psychological and health issues such as infertility and other disabilities. ${ }^{10,11}$

Unintended pregnancies are associated with high-risk antenatal behaviours such as smoking and excessive alcohol consumption, which increase the risk of poor pregnancy outcomes as well as adverse maternal outcomes. ${ }^{12,13}$ Unintended pregnancies also have serious environmental and political consequences, with overpopulation described as the world's worst environmental problem. ${ }^{14}$ Population growth has placed an unprecedented demand on our planet's finite resources while simultaneously increasing the amount and types of environmental pollution. Indeed, there have been calls to implement universal family planning services as a component of policy responses to environmental degradation. ${ }^{15,16}$ The benefits of increased access to family planning programmes and contraceptive use are immeasurable and include a myriad of advantages for individuals and societies: reduction in maternal and infant deaths, empowerment of women, prevention of unintended pregnancies, and avoidance of mother-to-child transmission of HIV or other infections and diseases. ${ }^{15,17}$ The economic consequences are also great. In the USA alone, the direct cost savings due to contraceptive use have been estimated at $\$ 19$ billion per year. ${ }^{7}$ 


\section{Dramatic changes in The Pill over time}

The Pill combines a progestogen, which primarily provides contraceptive efficacy by inhibiting ovulation, plus an estrogen, added to stabilise the endometrium for better cycle control and improved overall contraceptive effectiveness. The first COC, Enovid-10, contained $150 \mu \mathrm{g}$ mestranol, a synthetic estrogen, and $10 \mathrm{mg}$ norethynodrel, an androgen-derived progestogen. Although the ability of progesterone to inhibit ovulation had long been known, progesterone could not be used in these COC formulations because it is rapidly metabolised. Early efforts using the endogenous estrogen $17 \beta$-estradiol (E2) were also not successful, as resultant cycle control with monophasic and biphasic preparations was poor. ${ }^{18,19}$ Although numerous modifications in COC formulations followed, the initial monthly dosing regimen of 21 active pills followed by 7 placebo pills or pill-free days remained unchanged for decades. A 7-day break from active pilltaking was believed to be necessary to induce consistent withdrawal bleeding episodes, which was perceived by women as 'menstruation'. This was acknowledged to be very important in the initial psychological acceptance of The Pill. Monthly bleeding reassured women that The Pill was preventing pregnancy without disrupting menstruation. ${ }^{20}$ The decision to include a 7 -day break was based on the time required to sufficiently reduce circulating serum levels of the progestogen. The progestogen dose in the first COCs was high and 4-5 days were needed to reduce systemic concentrations to allow endometrial shedding. Taking into account individual variability, a 7-day break guaranteed that nearly all women taking The Pill would have a monthly withdrawal bleed. ${ }^{20}$

Over the 50 years since the introduction of Enovid-10, The Pill has evolved through various identifiable stages, including reductions in estrogen and progestogen doses, development of newer generations of progestogens, and modifications in dosing regimens (Figure 1).

\section{Lower doses of estrogen}

Mestranol, the first synthetic estrogen used in The Pill, is rapidly metabolised to ethinylestradiol (EE), which is the most commonly used estrogen in modern-day formulations. ${ }^{21}$ Doses of estrogen have been steadily reduced, from $150 \mu \mathrm{g}$ mestranol (equivalent to $100 \mu \mathrm{g} \mathrm{EE}$ ) to the COCs of today, which contain $\leq 35 \mu \mathrm{g} \mathrm{EE} .22$

Several studies have shown a two- to eight-fold increase in risk of venous thromboembolism (VTE) associated with COC use compared with non-use. ${ }^{23-28}$ This increased risk of VTE spurred the development of COCs containing lower doses of EE, with the aim of reducing side effects. ${ }^{21}$ Early reductions in the dose of EE from $100 \mu \mathrm{g}$ to $50 \mu \mathrm{g}$ were associated with a decreased risk of VTE. ${ }^{29,30}$ Further decreases in the risk of VTE have been noted in studies investigating pills containing $\leq 35 \mu \mathrm{g}$ $\mathrm{EE}$, although not all studies of pills with $<35 \mu \mathrm{g}$ EE were associated with lower VTE risk. ${ }^{23,24,31}$ In addition, as very low doses of EE are often associated with unacceptable bleeding patterns, the most appropriate sex steroid doses in COCs have been established within a relatively narrow range, which are not likely to vary further.

While the estrogen component of COCs functions primarily to provide stable and predictable cycle control, higher doses have been associated with adverse estrogenic events, such as nausea, breast tenderness and bloating. ${ }^{32}$ COCs containing 30-35 $\mu \mathrm{g}$ EE have been associated with more frequent estrogenic side effects compared with COCs containing $20 \mu \mathrm{g} \mathrm{EE} .32$ Conversely, a systematic review of 20 trials reported that several $20 \mu \mathrm{g}$ EE preparations resulted in higher rates of early trial discontinuation, mostly due to an increase in the frequency of unscheduled

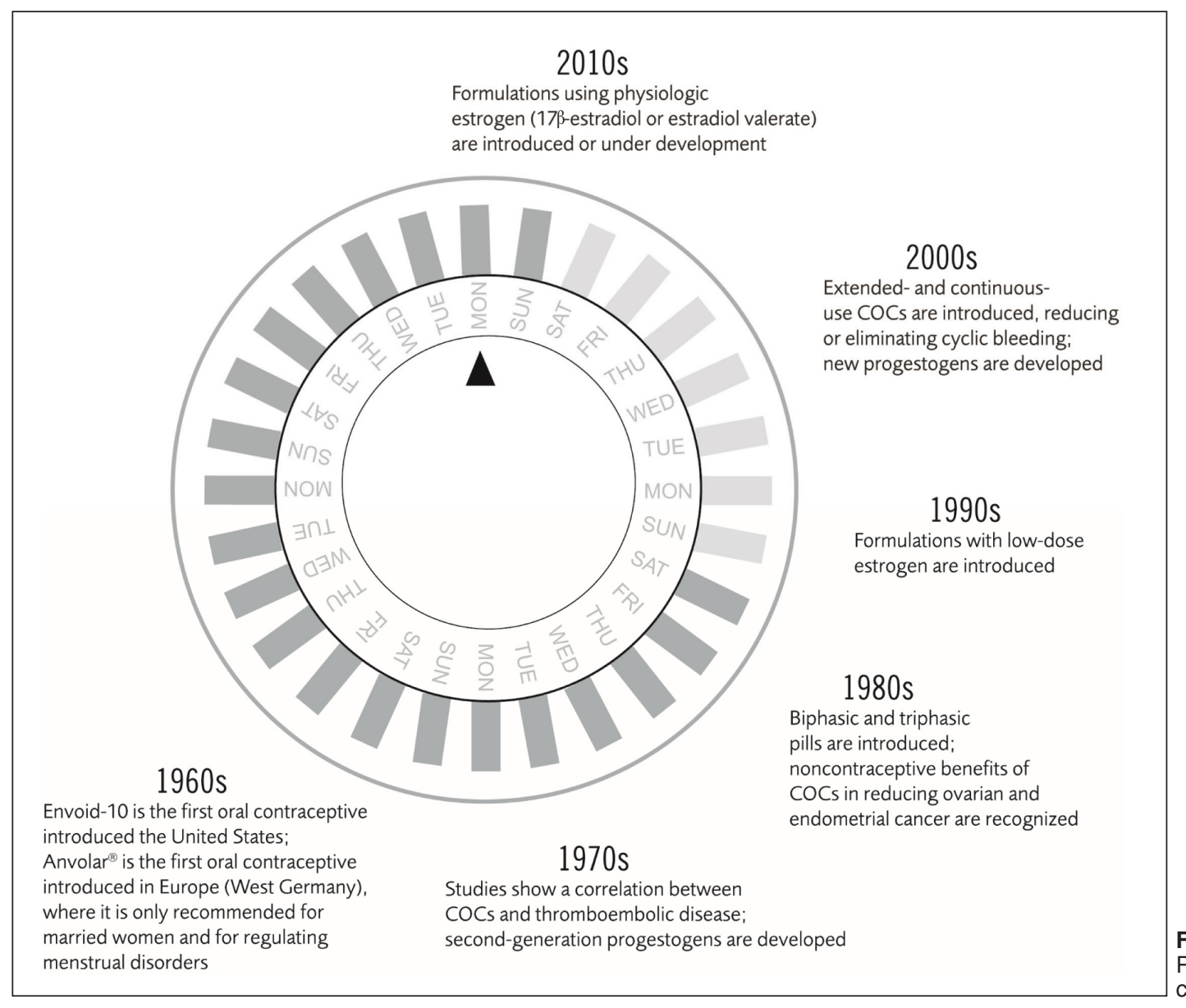

Figure 1 Evolution of "The Pill". COCs, combined oral contraceptives 
bleeding, including an increase in missed scheduled withdrawal bleeding episodes. ${ }^{33}$ Although these data imply that further reductions in the dose of EE may not be practical, the authors acknowledged that the studied COCs contained different types of progestogens and different dosing regimens (i.e. monophasic, biphasic and triphasic), which were likely to have influenced the measured outcomes. 33

\section{Newer progestogens}

There is general agreement that progestogen-only contraceptives do not increase the risk of VTE. However, since the 1990s there has been controversy regarding the potential influence of the progestogen type in COCs on VTE risk, a controversy which continues to this day. $23,24,34$

Most of the currently used progestogens are testosterone derived, but they differ in their relative binding affinities in vitro for various receptors known to affect gonadotropic, androgenic and metabolic activities. Binding affinities of progestogens to progesterone, androgen, estrogen, glucocorticoid and mineralocorticoid receptors are assessed to predict their potential clinical effects. 35 Ideally, a progestogen should be a high-affinity agonist for the progesterone receptor to promote ovulation inhibition but exhibit negligible or no activity at other steroid receptors to avoid unwanted side effects.

'First-generation' COCs contained progestogens called 'estranes' such as norethindrone, norethindrone acetate or ethynodiol diacetate, which were derived from testosterone. These COCs contained hormone doses (of both estrogen and progestogen) in excess of what was necessary for contraceptive efficacy and acceptable cycle control and were associated with more adverse events, both in terms of health risks, such as VTE, and side effects, such as nausea and bloating, compared with subsequent generations. ${ }^{36}$ So-called 'second-generation' COCs used progestogens called 'gonanes', such as levonorgestrel (LNG), which are more potent than their predecessors. In addition to having a higher affinity for the progesterone receptor (PR), these progestogens also have a higher affinity for androgen receptors. $35,37,38$ 'Third-generation' progestogens are also gonanes, derived from LNG but with less androgenic receptor affinity and metabolic impact. This group includes desogestrel (or its active metabolite 3-ketodesogestrel, also known as etonogestrel) and gestodene. Progesterone-derived protestogens, such as nomegestrol acetate (NOMAC), were developed to more closely mimic the anti-estrogenic, anti-androgenic and antimineralocorticoid properties of endogenous progesterone. NOMAC exhibits high selectivity for the progesterone receptor with some anti-androgenic properties and minimal or no effect on other steroid receptors at therapeutic doses.39-41 Other clinically used progestogens are more heterogeneous in their origin and effects. Drospirenone (DRSP), derived from $17 \beta-$ spirolactone, exhibits strong antimineralocorticoid activity with progestogenic activity and some anti-androgenic activity. 39,42-44 Dienogest (DNG), which is derived from testosterone and considered a hybrid progestogen, has antiandrogenic activity with no glucocorticoid, mineralocorticoid, estrogenic or anti-estrogenic activity. 37

\section{Different dosing regimens}

Most COCs are monophasic, delivering a single fixed dose throughout a woman's cycle. Multiphasic formulations containing EE were developed to reduce hormonal exposure over the 28-day cycle. In these phasic preparations, the dose of the progestogen or estrogen may vary during the cycle. ${ }^{45,46}$ However, two meta-analyses found that these complex formulations do not offer a safety, efficacy or overall clinical advantage over monophasic formulations. ${ }^{46}$

Perhaps a more important dosing advance has been the shortening or elimination of the 7-day pill-free interval (21/7) to improve cycle control while maintaining a low estrogen dose and potentially improving contraceptive efficacy. $47-49$ Currently, two approved formulations deliver 24 days of active treatment followed by 4 days of placebo (24/4), DRSP $3 \mathrm{mg} / \mathrm{EE} 20 \mu \mathrm{g}\left(\mathrm{Yaz}^{\circledR}\right.$; Bayer HealthCare Pharmaceuticals, Wayne, NJ, USA) and norethindrone $1 \mathrm{mg} / \mathrm{EE} 20 \mu \mathrm{g}$ (Loestrin ${ }^{\circledR} 24$ Fe; Warner Chilcott, Rockaway, NJ, USA). The efficacy and safety profiles of the 24/4 regimens are comparable to or more favourable than those of $21 / 7$ regimens. Initial evidence suggested that the 24/4 regimen confers better cycle control with less breakthrough bleeding compared with $21 / 7$ formulations containing $20 \mu \mathrm{g} \mathrm{EE} .48$ However, a recent study suggested the opposite may be true. This was a relatively short study of the DRSP-containing $24 / 4$ regimen over three cycles that demonstrated a greater absence of withdrawal bleeding and an increased frequency of unscheduled bleeding in the 24/4 group compared with the $21 / 7$ comparator group (EE $25 \mu \mathrm{g} /$ norgestimate triphasic pill regimen). The authors did not report whether women preferred or disliked the absence of withdrawal bleeding. .0 Nonetheless, the shorter pill-free interval of 4 days is associated with greater and more consistent suppression of ovarian activity compared with a 7-day pill-free interval, results in fewer unintended pregnancies, 51 and offers shorter episodes of withdrawal bleeding. $47,48,50$

COCs with extended active-pill regimens were developed to minimise the monthly withdrawal bleeding as physicians acknowledged the safety of amenorrhoea.52 Thus, other COCs designed to produce only four withdrawal bleeding episodes per year were approved as 84/4 regimens, including LNG $150 \mu \mathrm{g} / \mathrm{EE} 30 \mu \mathrm{g}$ (Seasonale ${ }^{\circledR}$; Duramed Pharmaceuticals, Pomona, NY, USA $)^{53}$ and LNG $150 \mu \mathrm{g} / \mathrm{EE} 30 \mu \mathrm{g}$ or EE $20 \mu \mathrm{g}$ plus $10 \mu \mathrm{g}$ EE instead of placebo for 7 days (Seasonique ${ }^{\circledR}$ or LoSeasonique ${ }^{\circledR}$, respectively; Duramed Pharmaceuticals, Pomona, NY, USA). 54

Finally, a continuous-cycle COC containing LNG $90 \mu \mathrm{g} / \mathrm{EE} 20 \mu \mathrm{g}\left(\right.$ Lybrel $^{\circledR}$; Pfizer, Inc., New York, NY, USA) has been approved for use in the USA. With this regimen, active hormone is taken continuously. ${ }^{55}$ Similar to the aforementioned extended-cycle regimens, this formulation is safe and effective but with a tendency for decreased bleeding compared with traditional regimens. ${ }^{55}$ A systematic review of continuous regimens concluded that women's satisfaction, discontinuation rates and bleeding patterns are similar to traditional regimens and that continuous dosing might improve menstruation-associated symptoms. ${ }^{56}$ However, it should be noted that in some studies of continuous regimens, discontinuation rates of over $40 \%$ were reported, mainly due to unscheduled bleeding events. ${ }^{53-55}$

Continuous tailored use of the COC is an option that is growing in popularity. 57,58 Women are advised to take their pill continuously until they experience breakthrough bleeding for 3-4 days, then take a pill break of 4 days. This approach improves cycle control compared with the continuous regimens and results in greater user satisfaction. ${ }^{20} \mathrm{~A}$ pill licensed specifically for such tailored use is expected to be available by 2012 .

\section{Non-contraceptive benefits and risks associated with The Pill}

When used properly, COCs have a very low contraceptive failure rate $(<1 \%)$, and they also confer a myriad of non- 
Table 1 Non-contraceptive benefits of combined oral contraceptive (COCs) adapted from Reid59

\section{Menses-related benefits}

- Improved menstrual cycle regularity

- Decreased blood loss

- Reduction in iron-deficiency anaemia

- Treatment of menorrhagia

- Treatment of dysmenorrhea

- Inducing amenorrhea for lifestyle considerations

- Prevention of menstrual migraines

Inhibition of ovulation

- Reduction in ovarian cysts

- Reduced risk of ectopic pregnancy

Other benefits

- Decrease in risk of endometrial cancer, ovarian cancer and colorectal cancer

- Treatment of acne or hirsutism

- Treatment of hyperandrogenic anovulation

- Improved bone mineral density

- Treatment of bleeding due to leiomyomas

- Treatment of pelvic pain due to endometriosis

- Positive effect on fibroadenomas/fibrocystic breast changes

- Positive effect on perimenopausal changes

- Improvement in pelvic inflammatory disease

- Improvement in rheumatoid arthritis

- Positive effect on bleeding disorders

contraceptive health benefits, which are briefly listed in Table 1.59 A recently published prospective cohort study of 46112 women aged $>39$ years found that users of oral contraception had a significantly lower all-cause mortality rate compared with never-users. ${ }^{60}$ Use of COCs has been shown to reduce the risk of some cancers, including endometrial, ovarian and colorectal cancer.59 Indeed, compared with never-users of oral contraceptives, everusers have been shown to have significantly lower mortality rates from all cancers (including large bowel/rectum, uterine and ovarian cancers) as well as lower mortality from ischemic heart disease. ${ }^{60}$ Decreased menstrual bleeding, reduced symptoms of premenstrual syndrome, and less dysmenorrhoea are also among the noncontraceptive benefits of COCs. 59,61 Additionally, COCs have been shown to ameliorate certain androgenic effects, such as acne and hirsutism. 59,61,62 However, use of COCs is not without risks, the most important of which are an increased risk of venous thromboembolic disease and, possibly, an increased risk of some types of cancers and adverse cardiovascular events. The need to reduce these risks has been an important factor driving the development of new COCs over the decades.

\section{Venous thromboembolism}

As described above, the increase in the risk of VTE is positively correlated with the degree of estrogen exposure. Although it has been suggested that certain newer progestogens are associated with a greater risk of VTE relative to older generation progestogens, ${ }^{23,24}$ these findings have been questioned owing to serious methodological problems associated with these studies. ${ }^{34,63}$ Results from studies that take confounding factors into account suggest VTE risk among COCs containing new or old progestogens is similar. ${ }^{26,64-67} \mathrm{~A}$ comprehensive analysis of VTE risk, which accounted for various confounders [e.g. weight, body mass index (BMI), smoking status, alcohol use, age, duration of COC use, and previous COC use], was performed among women using COCs containing LNG or norgestimate compared with gestodene or desogestrel. ${ }^{65}$ The study also distinguished between repeat users (i.e. those with interrupted use of the same COC) and switchers (i.e. those who switched between COC formulations). After adjusting for confounding factors, the study found no difference in the risk of VTE between COCs containing older and newer progestogen types. ${ }^{65}$ An important postmarketing surveillance study of 142475 woman-years monitored cardiovascular outcomes in COC users, particularly those using DRSP/EE compared with LNG COCs. Data from this European Active Surveillance Study (EURAS) suggest that the risk of VTE is similar for all COCs. ${ }^{67}$

It is well established that COC-induced VTE risk declines over time with continued use. The highest risk appears to occur during the early months after initiation, even in women who restart COC use after an interruption. 67,68 Patient characteristics are also important predictors of VTE risk in women using COCs. Women who have classic cardiovascular risk factors, such as tobacco use, high blood pressure, diabetes, obesity, history of thrombosis, or any coagulation abnormalities, are at greater risk $^{69}$ and should be carefully assessed for the most appropriate contraceptive. The Multiple Environmental and Genetic Assessment (MEGA) of risk factors for venous thrombosis found that women who used oral contraceptives (OCs) and had a BMI $\geq 30 \mathrm{~kg} / \mathrm{m}^{2}$ were at a 24 -fold greater risk of VTE compared with women who did not use oral contraceptives and had a normal BMI $<25 \mathrm{~kg} / \mathrm{m}^{2} .{ }^{70}$ The MEGA study also found that smokers who used oral contraceptives had a nine-fold increase in VTE risk compared with non-smokers who did not use COCs. ${ }^{71}$ These findings highlight the possibilities for prescriber bias in the studies published in the 1990s (and indeed most recently) that showed increased VTE risk with newer COCs. Thus, for example, if smoking is a risk factor for VTE and most smokers were preferentially given thirdgeneration pills, the greater risk of VTE due to smoking could have contributed to an apparent increase in VTE associated with third-generation pills (Figure 2). ${ }^{72}$ As highly effective progestogen-only contraceptives, which do not increase VTE risk, are available, the routine prescribing of COCs to women with a BMI $>30 \mathrm{~kg} / \mathrm{m}^{2}$, and particularly those with multiple risk factors for cardiovascular disease, is becoming difficult to justify. ${ }^{72}$ Age is also an important independent risk factor to consider, as older women are at greater risk of VTE when using COCs compared with younger women. ${ }^{73}$

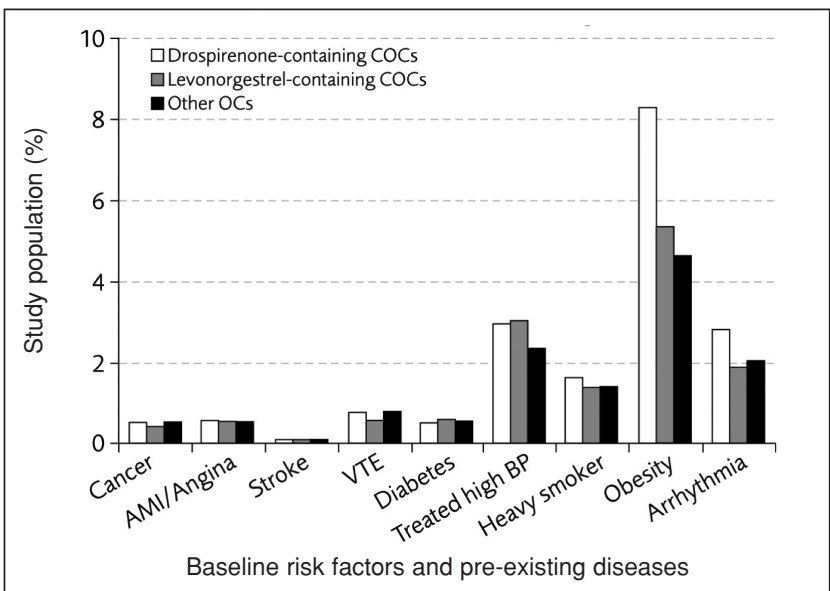

Figure 2 Baseline risk factors and preferential prescribing patterns: selected baseline risk factors and pre-existing conditions per oral contraceptive user cohort. $67 \mathrm{AMI}$, acute myocardial infarction; BP, blood pressure; COC, combined oral contraceptive; OC, oral contraceptive; VTE venous thromboembolism. Figure reprinted from Dinger JC, Heinemann LA, Kuhl-Habich D, The safety of a drospirenone-containing oral contraceptive: final results from the European Active Surveillance Study on Oral Contraceptives based on 142,475 women-years of observation. Contraception 2007; 75 : 344-354. (C) Elsevier, reprinted with permission 


\section{Cancer}

The association of various cancers with $\mathrm{COC}$ use has been reviewed in detail elsewhere. ${ }^{59,74,75}$ Available data indicate that oral contraceptives are positively correlated with some cancers, and neutral or negatively correlated with other cancers.

Regardless of the formulation, COCs have been shown to exert a protective effect against ovarian cancer (approximately $40 \%$ risk reduction), which becomes stronger with increasing duration of use and persists 15-20 years after pill discontinuation. ${ }^{76-78}$ Similarly, available data showed either a neutral 79,80 or favourable 81,82 effect of COCs with regard to colorectal cancer. Evidence showed an average $50 \%$ reduction in the risk of endometrial cancer in users of COCs compared with non-users. ${ }^{74,83}$ As with risk for ovarian cancer, this reduction in risk persisted for up to 20 years after COC discontinuation.

The impact of COCs on breast cancer risk is not as well clarified. A small increase in the risk of breast cancer was reported in current and former users of COCs by the Collaborative Group on Hormonal Factors in Breast Cancer. ${ }^{84}$ This risk was found to decrease over time after stopping COC use, with no difference seen after 10 years between users and non-users. Results from another study, however, did not find a significant increase in the risk of breast cancer in current or former users of COCs aged 35 to 64 years, regardless of estrogen dose or duration of use. ${ }^{85}$ Findings from two long-running cohort studies of low-dose COC use suggested that there was no increase in risk of breast cancer for women without a family history. ${ }^{78,86}$ Indeed, results from a study in women at highest risk for breast cancer as result of BRCA $1 / 2$ mutations or family history showed no increased risk for developing breast cancer among those in the study cohort using COCs. ${ }^{87}$

\section{New developments and future outlook}

Despite significant advances in oral contraception over the past five decades, unintended pregnancy remains unacceptably high. The reasons for this are multifaceted and include factors related to discrepancies in contraceptive availability, compliance or adverse events. New developments in combined oral contraception may ease some of these challenges and help reduce unintended pregnancies.

\section{New oral contraceptives with estradiol [E2 or estradiol valerate (E2V)]}

Advances in oral contraception can be generalised as progressive steps toward synthesising hormones that more closely mimic the actions of endogenous steroids in terms of concentration, receptor activity and selectivity, and clinical impact. While ongoing development of contraceptive progestogens has been undertaken to accomplish this goal, EE has been the estrogen component in nearly all COC formulations. EE became the preeminent contraceptive estrogenic substance because adding an ethinyl group at the $17 \beta$ position of the estradiol molecule acts to stabilise it for effective oral administration. While this has served to increase its bioavailability, EE consequently affects hepatic metabolism causing adverse estrogenic effects. ${ }^{88,89}$ As discussed previously, decreasing the dose of EE has served to reduce these effects; however, another approach has been to use compounds that include more physiological estrogens rather than EE. In theory, use of estrogens more closely related to endogenous E2 may result in more favourable safety and tolerability profiles. ${ }^{88}$ Additionally, using a molecule that is structurally identical to endogenous estradiol may help to increase acceptance and thus compliance among women. Previous experience with hormone replacement therapy among menopausal and postmenopausal women has demonstrated that such hormones are perceived more favourably compared with synthetic hormones that are dissimilar to their endogenous counterparts..$^{90,91}$ Similarly, premenopausal women who are concerned about the effects of exogenous hormones may be at greater ease using COCs containing 'natural' hormones. 92

Initial attempts to substitute EE with estradiol were largely unsuccessful, as these COCs were associated with poor cycle control. ${ }^{18,19,93-95}$ For example, in a study comparing two formulations that contained the same progestogen but different estrogens, more women using the COC with 'natural' estrogen discontinued and reported bleeding irregularities compared with those using the COC containing EE. ${ }^{93}$ This was largely due to the fact that these formulations were unable to achieve adequate bioavailability of E2 owing to first-pass metabolism, which may have been influenced by the type of progestogen used.

An oral contraceptive that combines E2V with DNG has been recently approved for use in the USA and Europe. DNG binds selectively to the progesterone receptor but with a weaker affinity relative to NOMAC and has a halflife of approximately 9-11 hours. ${ }^{96}$ It does not exhibit androgenic, estrogenic, glucocorticoid or mineralocortoid activity in vitro. ${ }^{97} \mathrm{E} 2 \mathrm{~V}$ is hydrolysed in the gastrointestinal tract and liver into a number of estrogens including E2.98 This four-phasic formulation provides effective contraceptive efficacy and acceptable cycle control similar to monophasic COCs.92,99

A combination of NOMAC with E2 is currently in development as a monophasic COC. Preliminary data indicate that this combination holds great promise, 100,101 not only because it contains E2 but also because NOMAC is a highly selective progesterone-derived progestogen, whose affinity for the progesterone receptor exceeds that of endogenous progesterone and which is devoid of estrogenic, androgenic, glucocorticoid or mineralocorticoid activity in vitro. $35,39,102$ NOMAC has a half-life of approximately 50 hours. ${ }^{35,103}$ In theory, this might translate into extended contraceptive protection for women who may miss a pill;51 however, this has not been evaluated in a clinical setting and there are no data available to support this benefit.. The dose of E2 (1.5 $\mathrm{mg}$ /day) in this preparation has been shown to produce serum concentrations similar to those observed during the early follicular and late luteal phase of the normal menstrual cycle. ${ }^{100}$

\section{Conclusions}

The introduction of The Pill in 1960 marked the beginning of revolutionary social change around the world. The half century since has brought major advances in oral contraception that have made The Pill safer and better tolerated. Incremental reductions in estrogen dose and development of new types of progestogens have served to decrease serious adverse events and improve overall tolerability . Most recently, pills delivering E2 offer a replacement to EE, which may further improve the tolerability and acceptability of COCs. This should further reduce the rate of unintended pregnancy worldwide by providing a greater selection of highly effective contraceptive options that may encourage women to use such methods for as long as they choose to be sexually active while not wishing to be pregnant. 


\section{Acknowledgements}

The authors want to thank Dr Anita Nelson for her input into the content and organisation of this manuscript. The authors also thank Susan Abulhawa, of Evidence Scientific Solutions, Philadelphia, PA, USA, for her editorial and medical writing support, which was funded by Schering Corporation, a division of Merck \& Co., Inc. The authors received no compensation or honoraria in association with this article, and they exercised sole and complete editorial responsibility for this paper.

\section{Statements on funding and competing interests}

Funding None identified.

Competing interests The authors have all, at one time or another, received sponsorship and/or funding in respect of consultancy work, giving lectures or conference attendance from one or more manufacturers of contraceptive drugs and products.

\section{References}

1 United Nations Department of Economic and Social Affairs Population Division. World Contraceptive Use. 2009. http://www.un.org/esa/population/publications/contraceptive 2009/contraceptive2009.htm [Accessed 11 June 2010].

2 World Health Organization (WHO). The World Health Report 2008 - Primary Health Care (Now More Than Ever). 2008. http://www.who.int/whr/2008/en/index.html [Accessed 11 June 2010].

3 Speidel JJ, Grossman RA. Family planning and access to safe and legal abortion are vital to safeguard the environment. Contraception 2007; 76: 415-417.

4 Hardee K. Population, gender, and climate change. BMJ 2009; 339: b4703.

5 Matlin SA, Samuels GMR. Sexual and reproductive health and climate change. Lancet 2009; $374: 949$.

6 Alan Guttmacher Institute (AGI). Sharing Responsibility: Women, Society, and Abortion Worldwide. New York, NY: Alan Guttmacher Institute, 1999.

7 Trussell $\mathrm{J}$. The cost of unintended pregnancy in the United States. Contraception 2007; 75: 168-170.

8 Singh S. Hospital admissions resulting from unsafe abortion estimates from 13 developing countries. Lancet 2006; 368 : 1887-1892.

9 Singh S, Wulf D, Hussain R, Bankole A, Sedge G. Abortion Worldwide: A Decade of Uneven Process. 2009 http://www.guttmacher.org/pubs/AWWfullreport.pdf [Accessed 11 June 2010].

10 Grimes DA, Benson J, Singh S, Romero M, Ganatra B, Okonofua FE, et al. Unsafe abortion: the preventable pandemic. Lancet 2006; 368: 1908-1919.

11 UNICEF. Maternal Mortality and Newborn Health. 2009. http://www.unicef.org/health/index_maternalhealth.htm [Accessed 17 May 2010].

12 Orr ST, James SA, Reiter JP. Unintended pregnancy and prenatal behaviors among urban, black women in Baltimore, Maryland: the Baltimore preterm birth study. Ann Epidemiol 2008; 18: 545-551.

13 Cheng D, Schwarz EB, Douglas E, Horon I. Unintended pregnancy and associated maternal preconception, prenatal and postpartum behaviors. Contraception 2009; 79: 194-198.

14 SUNY College of Environmental Science and Forestry. Worst Environmental Problem? Overpopulation, Experts Say. 20 April 2009. http://www.sciencedaily.com/releases/2009/04/ 090418075752.htm [Accessed 17 May 2010].

15 Bryant L, Carver L, Butler CD, Anage A. Climate change and family planning: least-developed countries define the agenda. Bull World Health Organ 2009; 87: 852-857.

16 Meyerson FAB. Population, development and global warming: averting the tragedy of the climate commons. Popul Environ 1998; 19: 443-463.

17 Cohen SA. Hiding in Plain Sight: The Role of Contraception in Preventing HIV. 2008. Guttmacher Policy Review. http://www.guttmacher.org/pubs/gpr/11/1/gpr110102.html [Accessed 11 June 2010].

18 Fruzzetti F, Bitzer J. Review of clinical experience with estradiol in combined oral contraceptives. Contraception 2010; 81: 8-15.

19 Hoffmann H, Moore C, Zimmermann H, Elger W, Schwarz S, Graser $\mathrm{T}$, et al. Approaches to the replacement of ethinylestradiol by natural 17beta-estradiol in combined oral contraceptives. Exp Toxicol Pathol 1998; 50: 458-464.

20 Nelson AL. Extended-cycle oral contraceptive pills with 10 microg ethinyl estradiol pills in place of placebo pills. Womens Health (Lond Engl) 2007; 3: 529-535.

21 Goldzieher JW, Stanczyk FZ. Oral contraceptives and individual variability of circulating levels of ethinyl estradiol and progestins. Contraception 2008; 78: 4-9.
22 Cerel-Suhl SL, Yeager BF. Update on oral contraceptive pills. Am Fam Physician 1999; 60: 2073-2084.

23 Lidegaard O, Lokkegaard E, Svendsen AL, Agger C. Hormonal contraception and risk of venous thromboembolism: national follow-up study. BMJ 2009; 339: b2890.

24 van Hylckama Vlieg A, Helmerhorst FM, Vandenbroucke JP, Doggen CJ, Rosendaal FR. The venous thrombotic risk of oral contraceptives, effects of oestrogen dose and progestogen type: results of the MEGA case-control study. BMJ 2009; 339: b2921.

25 World Health Organization Collaborative Study of Cardiovascular Disease and Steroid Hormone Contraception. Venous thromboembolic disease and combined oral contraceptives: results of international multicentre casecontrol study. Lancet 1995; 346: 1575-1582.

26 Farmer RD, Lawrenson RA, Thompson CR, Kennedy JG, Hambleton IR. Population-based study of risk of venous thromboembolism associated with various oral contraceptives. Lancet 1997; 349: 83-88.

27 Thorogood M, Mann J, Murphy M, Vessey M. Risk factors for fatal venous thromboembolism in young women: a casecontrol study. Int J Epidemiol 1992; 21: 48-52.

28 Vandenbroucke JP, Koster T, Briet E, Reitsma PH, Bertina RM, Rosendaal FR. Increased risk of venous thrombosis in oral-contraceptive users who are carriers of factor V Leiden mutation. Lancet 1994; 344: 1453-1457.

29 Gerstman BB, Piper JM, Tomita DK, Ferguson WJ, Stadel BV, Lundin FE. Oral contraceptive estrogen dose and the risk of deep venous thromboembolic disease. Am J Epidemiol 1991; 133: 32-37.

30 Vessey M, Mant D, Smith A, Yeates D. Oral contraceptives and venous thromboembolism: findings in a large prospective study. Br Med J (Clin Res Ed) 1986; 292: 526.

31 Lidegaard O, Edstrom B, Kreiner S. Oral contraceptives and venous thromboembolism: a five-year national case-control study. Contraception 2002; 65: 187-196.

32 Rosenberg MJ, Meyers A, Roy V. Efficacy, cycle control, and side effects of low- and lower-dose oral contraceptives: a randomized trial of 20 micrograms and 35 micrograms estrogen preparations. Contraception 1999; 60: 321-329.

33 Gallo MF, Nanda K, Grimes DA, Lopez LM, Schulz KF. 20 microg versus $>20$ microg estrogen combined oral contraceptives for contraception. Cochrane Database Syst Rev 2008; CD003989.

34 Shapiro S, Dinger J. Risk of venous thromboembolism among users of oral contraceptives: a review of two recently published studies. J Fam Plann Reprod Health Care 2010; 36: 33-38.

$35 \mathrm{Kuhl} \mathrm{H}$. Pharmacology of estrogens and progestogens: influence of different routes of administration. Climacteric 2005; 8(Suppl. 1): 3-63.

36 Petitti DB. Clinical practice. Combination estrogen-progestin oral contraceptives. N Engl J Med 2003; 349: 1443-1450.

37 Schindler AE, Campagnoli C, Druckmann R, Huber J Pasqualini JR, Schweppe KW, et al. Classification and pharmacology of progestins. Maturitas 2003; 46(Suppl. 1): S7-S16.

38 Ouzounian S, Verstraete L, Chabbert-Buffet N. Thirdgeneration oral contraceptives: future implications of current use. Expert Rev Obstet Gynecol 2008; 3: 189-201.

39 Sitruk-Ware R. Pharmacological profile of progestins. Maturitas 2004; 47: 277-283.

40 Sitruk-Ware R. Progestogens in hormonal replacement therapy: new molecules, risks, and benefits. Menopause 2002: 9: 6-15.

41 Kuhl H. Comparative pharmacology of newer progestogens. Drugs 1996; 51: 188-215.

42 Fuhrmann U, Krattenmacher R, Slater EP, Fritzemeier KH. The novel progestin drospirenone and its natural counterpart progesterone: biochemical profile and antiandrogenic potential. Contraception 1996; 54: 243-251.

43 Oelkers W, Berger V, Bolik A, Bahr V, Hazard B, Beier S, et al. Dihydrospirorenone, a new progestogen with antimineralocorticoid activity: effects on ovulation, electrolyte excretion, and the renin-aldosterone system in normal women. J Clin Endocrinol Metab 1991; 73: 837-842.

44 Oelkers W, Foidart JM, Dombrovicz N, Welter A, Heithecker $R$. Effects of a new oral contraceptive containing an antimineralocorticoid progestogen, drospirenone, on the renin-aldosterone system, body weight, blood pressure, glucose tolerance, and lipid metabolism. J Clin Endocrinol Metab 1995; 80: 1816-1821.

45 Endrikat J, Parke S, Trummer D, Schmidt W, Duijkers I, Klipping C. Ovulation inhibition with four variations of a four- 
phasic estradiol valerate/dienogest combined oral contraceptive: results of two prospective, randomized, openlabel studies. Contraception 2008; 78: 218-225.

46 Van Vliet HA, Grimes DA, Helmerhorst FM, Schulz KF. Biphasic versus monophasic oral contraceptives for contraception. Cochrane Database Syst Rev 2006; 3: CD002032.

47 Klipping C, Duijkers I, Trummer D, Marr J. Suppression of ovarian activity with a drospirenone-containing oral contraceptive in a 24/4 regimen. Contraception 2008; 78 : 16-25.

48 Nakajima ST, Archer DF, Ellman H. Efficacy and safety of a new 24-day oral contraceptive regimen of norethindrone acetate $1 \mathrm{mg} / \mathrm{ethinyl}$ estradiol 20 micro g (Loestrin $24 \mathrm{Fe}$ ). Contraception 2007; 75: 16-22.

49 Spona J, Elstein M, Feichtinger W, Sullivan H, Ludicke F, Muller $U$, et al. Shorter pill-free interval in combined oral contraceptives decreases follicular development. Contraception 1996; 54: 71-77.

50 Kaunitz AM, Burkman RT, Fisher AC, Laguardia KD. Cycle control with a 21-day compared with a 24-day oral contraceptive pill: a randomized controlled trial. Obstet Gynecol 2009; 114: 1205-1212.

51 Dinger J. The International Active Surveillance Study of Women taking Oral Contraceptives (INAS-OC) study: ACOG 2009: preliminary findings favor 24-day regimen of drospirenone and ethinyl estradiol for contraception. Paper presented at the 57th Annual Clinical Meeting of the American College of Obstetricians and Gynecologists (ACOG), 57th Annual Clinical Meeting, Chicago, IL, USA, 2-6 May 2009.

52 Wright KP, Johnson JV. Evaluation of extended and continuous use oral contraceptives. Ther Clin Risk Manag 2008; 4: 905-911.

53 Anderson FD, Hait H. A multicenter, randomized study of an extended cycle oral contraceptive. Contraception 2003; 68: 89-96.

54 Anderson FD, Gibbons W, Portman D. Safety and efficacy of an extended-regimen oral contraceptive utilizing continuous low-dose ethinyl estradiol. Contraception 2006; 73: 229-234.

55 Archer DF, Jensen JT, Johnson JV, Borisute H, Grubb GS, Constantine GD. Evaluation of a continuous regimen of levonorgestrel/ethinyl estradiol: phase 3 study results. Contraception 2006; 74: 439-445.

56 Edelman AB, Gallo MF, Jensen JT, Nichols MD, Schulz KF Grimes DA. Continuous or extended cycle vs. cyclic use of combined oral contraceptives for contraception. Cochrane Database Syst Rev 2005; CD004695.

57 Coffee AL, Sulak PJ, Kuehl TJ. Long-term assessment of symptomatology and satisfaction of an extended oral contraceptive regimen. Contraception 2007; 75: 444-449.

58 Szarewski A. Sisters doing it for themselves. J Fam Plann Reprod Health Care 2009; 35: 71-72.

59 ACOG Practice Bulletin No. 110: noncontraceptive uses of hormonal contraceptives. Obstet Gynecol 2010; 115: 206-218.

60 Hannaford PC, Iversen L, Macfarlane TV, Elliott AM, Angus V, Lee AJ. Mortality among contraceptive pill users: cohort evidence from Royal College of General Practitioners' Oral Contraception Study. BMJ 2010; 340: c927.

61 Burkman R, Schlesselman JJ, Zieman M. Safety concerns and health benefits associated with oral contraception. $A m \mathrm{~J}$ Obstet Gynecol 2004; 190: S5-S22.

62 Arowojolu AO, Gallo MF, Lopez LM, Grimes DA, Garner SE. Combined oral contraceptive pills for treatment of acne. Cochrane Database Syst Rev 2009; CD004425

63 Reid RL, Mansour D, de Vries C, Verhaeghe J, Boschitsch E, Gompel A, Birkhauser M, Krepelka P, Dulicek P, Iversen OE, Khamoshima M, Vrabic Dezman L, Fruzetti F, Szarewski A Wilken-Jensen C, Seidman D, Kaaja R, Shapiro S. Oral Contraceptives and Venous Thromboembolism. Consensus Opinion from an International Workshop held in Berlin, Germany in December 2009. J Fam Plann Reprod Health Care 2010; 36: 117-122.

64 Todd J, Lawrenson R, Farmer RD, Williams TJ, Leydon GM. Venous thromboembolic disease and combined oral contraceptives: a re-analysis of the MediPlus database. Hum Reprod 1999; 14: 1500-1505.

65 Suissa S, Spitzer WO, Rainville B, Cusson J, Lewis M, Heinemann L. Recurrent use of newer oral contraceptives and the risk of venous thromboembolism. Hum Reprod 2000; 15: 817-821.

66 Farmer RD, Todd JC, Lewis MA, MacRae KD, Williams TJ. The risks of venous thromboembolic disease among German women using oral contraceptives: a database study. Contraception 1998; 57: 67-70.
67 Dinger JC, Heinemann LA, Kuhl-Habich D. The safety of a drospirenone-containing oral contraceptive: final results from the European Active Surveillance Study on oral contraceptives based on 142475 women-years of observation. Contraception 2007: 75: 344-354.

68 Suissa S, Blais L, Spitzer WO, Cusson J, Lewis M, Heinemann L. First-time use of newer oral contraceptives and the risk of venous thromboembolism. Contraception 1997; 56: 141-146.

69 Blumenthal PD, Edelman A. Hormonal contraception. Obstet Gynecol 2008; 112: 670-684.

70 Pomp ER, le Cessie S, Rosendaal FR, Doggen CJ. Risk of venous thrombosis: obesity and its joint effect with oral contraceptive use and prothrombotic mutations. $\mathrm{Br} J$ Haematol 2007; 139: 289-296.

71 Pomp ER, Rosendaal FR, Doggen CJ. Smoking increases the risk of venous thrombosis and acts synergistically with oral contraceptive use. Am J Hematol 2008; 83: 97-102.

72 Szarewski A. Choice of contraception. Obstet Gynaecol Repro Med 2009; 19: 323-326.

73 Girolami A, Spiezia L, Girolami B, Zocca N, Luzzatto G. Effect of age on oral contraceptive-induced venous thrombosis. Clin Appl Thromb Hemost 2004; 10: 259-263.

74 Huber JC, Bentz EK, Ott J, Tempfer CB. Non-contraceptive benefits of oral contraceptives. Expert Opin Pharmacother 2008: 9: 2317-2325.

75 La Vecchia C, Bosetti C. Oral contraceptives and neoplasms other than breast and female genital tract. Eur J Cancer Prev 2009; 18: 407-411.

76 Centers for Disease Control and Prevention and National Institute of Child Health and Human Development. The reduction in risk of ovarian cancer associated with oralcontraceptive use. The Cancer and Steroid Hormone Study of the Centers for Disease Control and the National Institute of Child Health and Human Development. N Engl J Med 1987; 316: 650-655.

77 Schlesselman JJ. Risk of endometrial cancer in relation to use of combined oral contraceptives. A practitioner's guide to meta-analysis. Hum Reprod 1997; 12: 1851-1863.

78 Vessey M, Painter R. Oral contraceptive use and cancer. Findings in a large cohort study, 1968-2004. Br J Cancer 2006; 95: 385-389.

79 Vessey M, Painter R, Yeates D. Mortality in relation to oral contraceptive use and cigarette smoking. Lancet 2003; 362: 185-191.

80 Kabat GC, Miller AB, Rohan TE Oral contraceptive use, hormone replacement therapy, reproductive history and risk of colorectal cancer in women. Int J Cancer 2008; 122: 643-646.

81 Fernandez E, La Vecchia C, Balducci A, Chatenoud L, Franceschi S, Negri E. Oral contraceptives and colorectal cancer risk: a meta-analysis. Br J Cancer 2001; 84: 722-727.

82 Levi F, Pasche C, Lucchini F, La Vecchia C. Oral contraceptives and colorectal cancer. Dig Liver Dis 2003; 35: 85-87.

83 Prentice RL, Thomas DB. On the epidemiology of oral contraceptives and disease. Adv Cancer Res 1987; 49: 285-401.

84 Collaborative Group on Hormonal Factors in Breast Cancer. Breast cancer and hormonal contraceptives: collaborative reanalysis of individual data on 53297 women with breast cancer and 100239 women without breast cancer from 54 epidemiological studies. Lancet 1996; 347: 1713-1727.

85 Marchbanks PA, McDonald JA, Wilson HG, Folger SG, Mandel MG, Daling JR, et al. Oral contraceptives and the risk of breast cancer. N Engl J Med 2002; 346: 2025-2032.

86 Hannaford PC, Selvaraj S, Elliott AM, Angus V, Iversen L, Lee AJ. Cancer risk among users of oral contraceptives: cohort data from the Royal College of General Practitioners' Oral Contraception Study. BMJ 2007; 335: 651.

87 Milne RL, Knight JA, John EM, Dite GS, Balbuena R, Ziogas $A$, et al. Oral contraceptive use and risk of early-onset breast cancer in carriers and noncarriers of BRCA1 and BRCA2 mutations. Cancer Epidemiol Biomarkers Prev 2005; 14 350-356.

88 Sitruk-Ware R. New progestagens for contraceptive use. Hum Reprod Update 2006; 12: 169-178.

89 Ansbacher R. The pharmacokinetics and efficacy of different estrogens are not equivalent. Am J Obstet Gynecol 2001; 184: 255-263.

90 Fugh-Berman A, Bythrow J. Bioidentical hormones for menopausal hormone therapy: variation on a theme. $J$ Gen Intern Med 2007; 22: 1030-1034.

91 Adams C, Cannell S. Women's beliefs about "natural" hormones and natural hormone replacement therapy. Menopause 2001; 8: 433-440. 
92 Mansour D. Qlaira ${ }^{\circledR}$ : a 'natural' change of direction. J Fam Plann Reprod Health Care 2009; 35: 139-142.

93 Koetsawang S, Mandlekar AV, Krishna UR, Uurandare VN Deshpande CK, et al.; for the Task Force on Oral Contraceptives. A randomized, double-blind study of two combined oral contraceptives containing the same progestogen, but different estrogens. Contraception 1980; 21: 445-459.

94 Wenzl R, Bennink HC, van Beek A, Spona J, Huber J. Ovulation inhibition with a combined oral contraceptive containing $1 \mathrm{mg}$ micronized 17 beta-estradiol. Fertil Steril 1993; 60: 616-619.

95 Hirvonen $\mathrm{E}$, Allonen $\mathrm{H}$, Anttila M, Kulmala $\mathrm{Y}$, Ranta $\mathrm{T}$, Rautiainen $\mathrm{H}$, et al. Oral contraceptive containing natural estradiol for premenopausal women. Maturitas 1995; 21: 27-32.

96 Mueck AO, Seeger H, Buhling KJ. Why use of dienogest for the first contraceptive pill with estradiol? Gynecol Endocrinol 2009; August 11, 1-5 [Epub ahead of print] DOI: 10.3109/ 09513590903184167

97 Sasagawa S, Shimizu Y, Kami H, Takeuchi T, Mita S, Imada $\mathrm{K}$, et al. Dienogest is a selective progesterone receptor agonist in transactivation analysis with potent oral endometrial activity due to its efficient pharmacokinetic profile. Steroids 2008; 73: 222-231.

98 Dusterberg B, Nishino Y. Pharmacokinetic and pharmacological features of oestradiol valerate. Maturitas 1982; 4: 315-324.

99 Ahrendt HJ, Makalova D, Parke S, Mellinger U, Mansour D. Bleeding pattern and cycle control with an estradiol-based oral contraceptive: a seven-cycle, randomized comparative trial of estradiol valerate/dienogest and ethinyl estradiol/levonorgestrel. Contraception 2009; 80: 436-444.

100 Chabbert-Buffet N. Synergistic effect of $17 \beta$-estradiol and nomegestrol acetate used in a new monophasic oral contraceptive. Paper presented at the 8th Congress of the European Society of Gynecology, Rome, Italy, 10-13 September 2009.

101 Serfaty D, Christin Maitre S, Ochsenbein E, Thomas J-L. Comparison of two regimens of new monophasic oral contraceptive combining 17 beta-estradiol and nomegestrol acetate. Paper presented at the XIX FIGO World Congress of Gynecology and Obstetrics, Cape Town, South Africa, 4-9 October 2009.

102 Catherino WH, Jordan VC. Nomegestrol acetate, a clinically useful 19-norprogesterone derivative which lacks estrogenic activity. J Steroid Biochem Mol Biol 1995; 55: 239-246.

103 Ezan E, Benech H, Bucourt R, Ardouin T, Tchernatinsky C, Thomas JL, et al. Enzyme immunoassay for nomegestrol acetate in human plasma. J Steroid Biochem Mol Biol 1993; 46: $507-514$

\section{FACULTY OF SEXUAL \& REPRODUCTIVE HEALTHCARE MEMBERSHIP EXAMINATION}

The Membership Examination (MFSRH) consists of:

Part 1 Multiple Choice Question paper (MCQ)

The London-based examination is held annually in April and October. Applications for the 14 April 2011 examination must be received by 4 January 2011. Applications for the 19 October 2011 examination must be received by 1 July 2011. The new syllabus for the Part 1 is on the Faculty website.

$\square$ Evidence Based Commentary (EBC)

Candidates can view the released topic and candidate guidance notes for EBC on the Faculty website. There is an absolute deadline of $\mathbf{3 1}$ August 2011 to submit the EBC on this topic.

\section{$\square$ Part 2 Examination (CRQ, SAQ, OSCE)}

This all-day examination will consist of:

- $\quad$ Critical Reading Question examination paper (CRQ)

- Extended Matching Question examination paper (EMQ)

- Objective Structured Clinical Examination (OSCE)

Applications for the MFSRH Part 2 held on 15 June 2011 must be received by 4 January 2011. The new Part 2 Syllabus is on the Faculty website.

The qualification is subject to re-certification every 5 years.

For the current MFSRH Examination Regulations, information on all components of the MFSRH examination and application forms, please visit the Faculty of Sexual and Reproductive Healthcare website: www.fsrh.org (Training \& Exams and Membership Exam) or e-mail Denise Pickford: denise@fsrh.org.

\section{JOIN THE PANEL OF MFSRH EXAMINERS}

The Faculty Examination Committee invites applications to join the panel of MFSRH Examiners for the Membership Examination. Applications are sought only from those able to fully commit to all examiner duties and who meet the following criteria:

- To be accredited Members of the Faculty and active clinically in the sphere of the Faculty or to be Clinicians, of equivalent status, with an interest in Sexual and Reproductive Healthcare but whose speciality is Genitourinary Medicine (GUM), Public Health Medicine, Gynaecology or Primary Care.

- To be able to show excellence in the quality of patient care, research skills or teaching skills relevant to the sphere of the Faculty.

To hold or have held the Faculty Letter of Competence in Medical Education or equivalent.

Further information and the examiner CV application form are available on the Faculty website:

www.fsrh.org (Training \& Exams, Membership Exam, MFSRH Examiners). The closing date for applications is 6 January 2011 and the form should be sent to the Examination Secretary, Examinations, FSRH, 27 Sussex Place, Regent's Park, London NW1 4RG, UK. Tel: +44 (0) 207724 5629. Fax: +44 (0) 2077235333. 